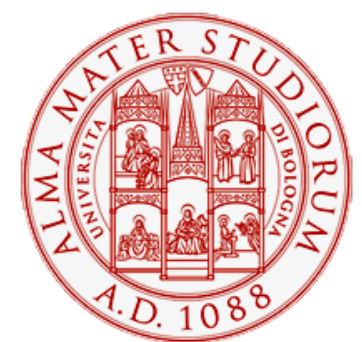

Alma Mater Studiorum - Università di Bologna DEPARTMENT OF ECONOMICS

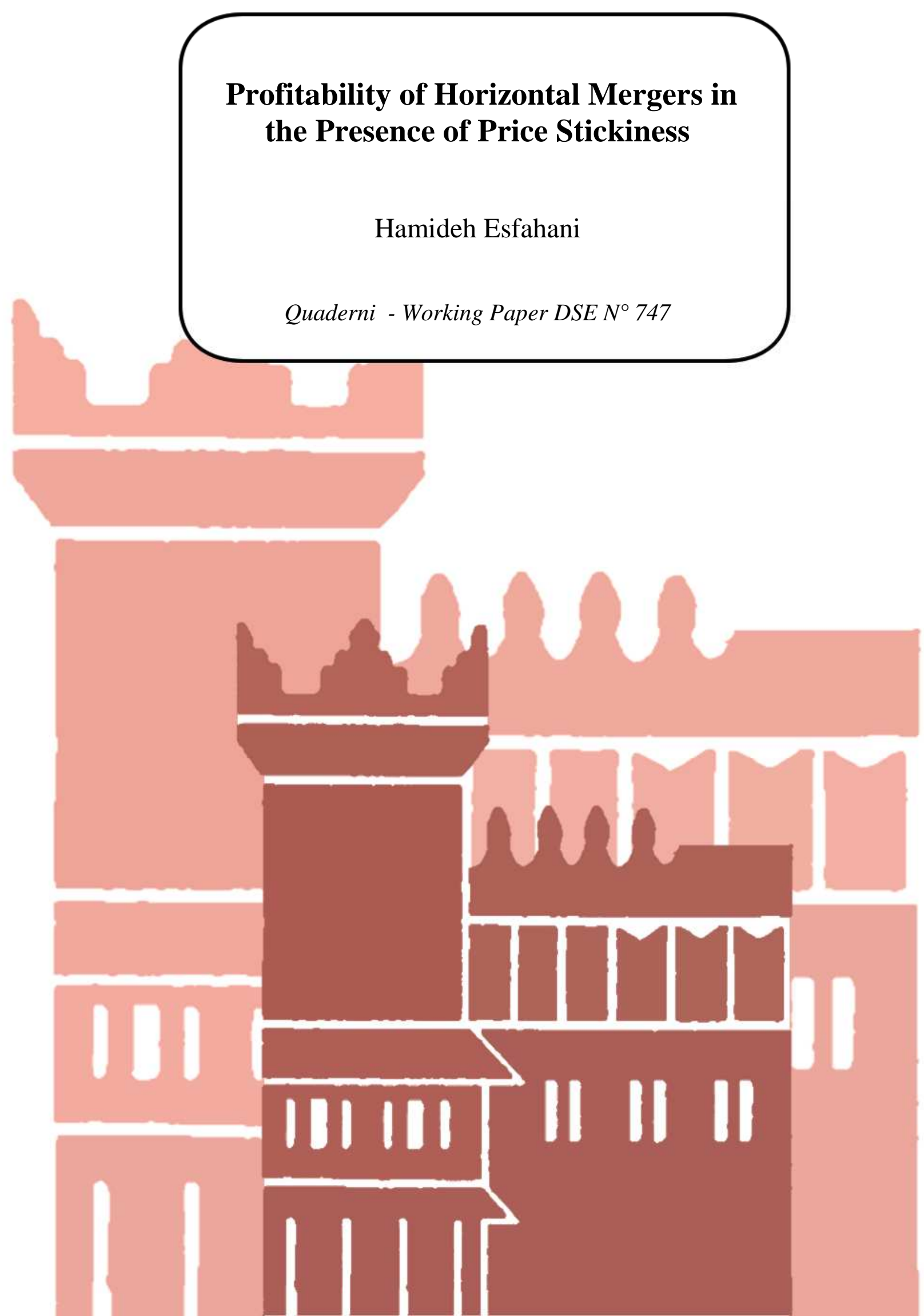




\title{
Profitability of Horizontal Mergers in the Presence of Price Stickiness*
}

\author{
Hamideh Esfahani \\ Department of Economics, University of Bologna \\ Strada Maggiore 45, 40125 Bologna, Italy \\ hamideh.esfahani2@unibo.it
}

First draft: December 2009

This draft: April 2011

\begin{abstract}
In this paper, we investigate the profitability of horizontal mergers of firms with price adjustments. We take a differential game approach and both the open-loop as well as the closed-loop equlibria are considered. We show that the merger incentive is determined by how fast the price adapts to the equilibrium level.
\end{abstract}

Keywords: Horizontal mergers, Differential game, Sticky price

JEL Classification: C73, D43, L13

\footnotetext{
${ }^{*}$ I would like to thank Luca Lambertini for his helpful comments and advice throughout this study. I also wish to thank Davide Dragone, Arsen Palestini and seminar participants at EBIM workshop, PhD forum at university of Bologna, ACDD, EUNIP and SAEe conferences and ASSET annual meeting for useful comments. Financial support from the University of Bologna is gratefully acknowledged.
} 


\section{Introduction}

When quantity-setting firms compete in a homogenous product industry with symmetric cost and the same demand functions, horizontal merger is modelized as an exogenous change in market structure. As a result, the level of competition decreases which increases the market price and market power of firms as well. In the case of linear demand and cost functions, the resulting anticompetitive forces are mostly to the benefit of outsiders and mergers are advantageous to the merging firm just in the circumstance that market share of merging firm is extremely high, at least $80 \%$ which is almost merging to a monopoly (Salant, Switzer and Reynolds, 1983 (henceforth SSR); Gaudet and Salant, 1991, 1992). Keeping everything the same, this threshold will be reduced to $50 \%$ (which is again a considerable market share) provided that the merged entity is not restricted to remain a Cournot player after the merger (Levin, 1990) or any demand function which satisfies the second-order conditions is allowed (Cheung, 1992). There are other studies showing that mergers are privately profitable if they are leader-generating (in industries where about less than one-third of the firms are leaders) (Daughety, 1990), or if merger generates synergies

(Perry and Porter, 1985; Farrell and Shapiro, 1990). However, the incentive to merge always exists once price is employed as the strategic variable rather than quantity. In a differentiated product industry, Deneckere and Davidson (1985) demonstrate that mergers of any size are beneficial if firms are engaged in a price-setting game.

We want to conduct an investigation into the consequences of horizontal mergers in oligopoly Cournot competition in the presence of price stickiness. When prices are sticky, for a given level of output the actual market price of a product does not adjust instantaneously to the price indicated by its demand function and price adjustment takes time. Since prices evolve over time we need a dynamic framework to investigate the effect of price stickiness on the profitability of horizontal mergers.

Using an oligopolistic differential game model with sticky prices in the specific case of instantaneous price adjustment, Dockner and Gaunersdorfer (2001) through a numerical analysis show that, contrary to the static game, in a dynamic Cournot game where firms use feedback strategies mergers are always profitable independently of the number of merging firms. Their result suggests that to analyzing merger, it is important to consider the nature of competition in the industry. Besides focusing on the same issue analytically, 
Benchekroun (2003) shows that when firms use open-loop strategies merger is profitable only if the market share of the merged firm is significant enough, very similar to the SSR results, which put more emphasis on the role of feedback strategies to create incentive to merge.

In this paper, we take a general approach without introducing specific assumptions on the degree of price stickiness to investigate the bearings of price dynamics. Scale economies as a motive for merger is ruled out by assumption because we would like to concentrate on the incentives to merge that are generated by price dynamics. To this end, we take a differential game approach to price dynamics introduced by Simaan and Takayama (1978) and Fershtman and Kamien (1987). We take into consideration both the open-loop and closed-loop (memoryless) ${ }^{1}$ equilibria to investigate how the speed of adjustment can affect the profitability of horizontally merged firms. There emerges, when price adjust with a very sticky mechanism, mergers with a small number of insiders but large number of outsiders are also privately profitable even if firms play open-loop. Furthermore, by figuring out the least market share required for merger to be profitable when price adjusts instantaneously, we revisit the closed-loop effect to generate incentive to merge.

The remainder of the paper is organized as follows. Section 2 contains the layout of the model. Sections 3 illustrate the open-loop and closed-loop equilibria. The assessment of incentives towards mergers is given in section 4 . Section 5 concludes the paper.

\section{The setup}

Consider a dynamic oligopoly market where $n$ symmetric firms, at any $t \in[0, \infty)$, produce quantities $q_{i}(t) \geq 0, i \in\{1,2, \ldots, n\}$, of the same homogeneous good with concave

\footnotetext{
${ }^{1}$ Broadly speaking, the main difference between the open-loop equilibrium on one hand and the feedback and closed-loop equilibria on the other is that the former does not take into account strategic interaction between players through the evolution of state variables over time and the associated adjustment in controls. Under the open-loop rule, players choose their respective plans at the initial date and commit to them forever. Therefore, in general, open-loop equilibria are not subgame perfect, in that they are only weakly time consistent since players make their action 'by the clock' only.

A further distinction can be made between the closed-loop equilibrium and the feedback equilibrium, which are both strongly time consistent and, therefore, subgame perfect since, at any date $\tau$, players decide 'by the stock' of all state variables. However, while the closed-loop memoryless equilibrium takes into account the initial and current levels of all state variables, the feedback equilibrium accounts for the accumulated stock of each state variable at the current date. Hence, the feedback equilibrium is a closed-loop equilibrium, while the opposite is not true in general [2].
} 
technologies described by the quadratic cost functions

$$
C_{i}(t)=c q_{i}(t)+\frac{1}{2} q_{i}^{2}(t), \quad c>0
$$

In each period, the product price, $\hat{p}(t)$, is determined by means of the inverse demand function

$$
\hat{p}(t)=A-\sum_{i=1}^{n} q_{i}(t) .
$$

However, since price is sticky, the actual market price does not adjust instantaneously to the price given by the demand function. That is, $\hat{p}(t)$ will differ from the current price level, $p(t)$, and price moves according to the following equation

$$
\frac{d p(t)}{d t} \equiv \dot{p}(t)=s\{\hat{p}(t)-p(t)\}
$$

where $s \in[0, \infty)$ is a constant that determines the speed of price adjustment. The lower is $s$, the higher is the degree of price stickiness. When $s$ goes to infinity, price is not sticky and the actual market price is equal to the price given by the demand function.

The instantaneous profit function of firm $i$ is

$$
\pi_{i}(t)=q_{i}(t)\left[p(t)-c-\frac{1}{2} q_{i}(t)\right] .
$$

Therefore, the maximization problem of firm $i$ is

$$
\max _{q_{i}(t)} J_{i}=\int_{0}^{\infty} e^{-\rho t} q_{i}(t)\left[p(t)-c-\frac{1}{2} q_{i}(t)\right] d t,
$$

subject to (3), $p(0)=p_{0}$ and $p(t) \geq 0$ for all $t \in[0, \infty)$. The factor $e^{-\rho t}$ discounts future gains, and the discount rate $\rho$ is assumed to be constant and equal across firms.

We solve the differential game using both the open-loop information structure where firms choose their production plans at the initial date and stick to them for the whole time horizon and the closed-loop memoryless information structure where firms' quantity choices at any time depend on the initial and current levels of all state variables (here, price).

According to Cellini and Lambertini (2004), the steady state levels of the price and the individual output of a dynamic oligopoly game with price adjustments which are the premerger solution of our problem at the open-loop Nash equilibrium are 


$$
p^{O L}=A-n q^{O L} ; \quad q^{O L}=\frac{(A-c)(\rho+s)}{(1+n) \rho+(2+n) s},
$$

and at the closed-loop Nash equilibrium are

$$
p^{C L}=A-n q^{C L} ; \quad q^{C L}=\frac{(A-c)(\rho+n s)}{s+(1+n)(\rho+n s)} .
$$

The corresponding single period profits are

$$
\pi^{O L}=\frac{(A-c)^{2}(\rho+s)(\rho+3 s)}{2[(1+n) \rho+(2+n) s]^{2}} ; \quad \pi^{C L}=\frac{(a-c)^{2}(\rho+n s)(\rho+(2+n) s)}{2[s+(1+n)(\rho+n s)]^{2}} .
$$

The superscripts $O L$ and $C L$ indicate the open-loop and closed-loop equilibrium level of a variable, respectively.

For later reference, let us also note that in the static game where the demand and cost functions are specified by (1) and (2) in turn, the equilibrium prices when firms play à la Cournot and à la Bertrand respectively are

$$
\begin{aligned}
p^{C N} & =\frac{2 A+n c}{n+2}, \\
p^{B N} & =\frac{A+n c}{n+1} .
\end{aligned}
$$

\section{The merger equilibrium}

In this section, we consider a horizontal merger of $m$ firms $(1<m \leq n)$ where they act collusively to maximize their discounted joint profits. ${ }^{2} n-m$ firms stay outside the merger. Hence, the differential game becomes

$$
\begin{gathered}
\max _{\bar{q}_{i}} J^{m}=\int_{0}^{\infty} e^{-\rho t}\left[(p(t)-c) \sum_{i=1}^{m} \bar{q}_{i}(t)-\frac{1}{2} \sum_{i=1}^{m} \bar{q}_{i}^{2}(t)\right] d t, \quad i=1, \ldots, m \\
\max _{q_{j}(t)} J_{j}=\int_{0}^{\infty} e^{-\rho t} q_{j}(t)\left[p(t)-c-\frac{1}{2} q_{j}(t)\right] d t, \quad j=m+1, \ldots, n
\end{gathered}
$$

subject to

$$
\frac{d p(t)}{d t} \equiv \dot{p}(t)=s\left\{A-\sum_{i=1}^{m} \bar{q}_{i}(t)-\sum_{j=m+1}^{n} q_{j}(t)-p(t)\right\}
$$

\footnotetext{
${ }^{2}$ Given the convex cost function, it is optimal to produce with all $m$ firms, and not to concentrate production on one firm only.
} 
and to the initial conditions $p(0)=p_{0}$ and $p(t) \geq 0$.

$\bar{q}_{i}(t) \geq 0, i \in\{1,2, \ldots, m\}$ and $q_{j}(t) \geq 0, j \in\{m+1, \ldots, n\}$ denote, in turn, the output level of an insider and an outsider. $J^{M}$ and $J_{j}$ represent the problem of the merging firm and outsiders, respectively.

According to (9), (10) and (11), the Hamiltonian functions of merging firms and outsiders are

$$
\begin{aligned}
H^{M}(t)= & e^{-\rho t}\left\{(p(t)-c) \sum_{i=1}^{m} \bar{q}_{i}(t)-\frac{1}{2} \sum_{i=1}^{m} \bar{q}_{i}^{2}(t)\right. \\
& \left.+\bar{\lambda}_{i}(t) s\left[A-\sum_{i=1}^{m} \bar{q}_{i}(t)-\sum_{j=m+1}^{n} q_{j}(t)-p(t)\right]\right\}, \\
H_{j}(t)= & e^{-\rho t}\left\{q_{j}(t)\left[p(t)-c-\frac{1}{2} q_{j}(t)\right]\right. \\
& \left.+\lambda_{j}(t) s\left[A-\sum_{i=1}^{m} \bar{q}_{i}(t)-\sum_{j=m+1}^{n} q_{j}(t)-p(t)\right]\right\},
\end{aligned}
$$

where $\lambda_{j}(t)=\mu_{j}(t) e^{\rho t}$ and $\bar{\lambda}_{i}(t)=\bar{\mu}_{i}(t) e^{\rho t}$ and $\mu_{j}(t)$ and $\bar{\mu}_{i}(t)$ are the co-state variables associated with $p(t)$.

\subsection{Open-loop equilibrium}

After the merger, at the open-loop Nash equilibrium, the steady state levels of the price and the output of merging firm and outsiders are

$$
\begin{gathered}
p_{\text {post }}^{O L}=A-q_{M}^{O L}-(n-m) q_{O}^{O L}, \\
q_{M}^{O L}=\alpha m(\rho+2 s), \quad q_{O}^{O L}=\alpha(\rho+s+m s),
\end{gathered}
$$

where

$$
\alpha=\frac{(A-c)(\rho+s)}{(n+1) \rho^{2}+[2 n+m(n-m+2)+3] \rho s+[n+m(n-m+3)+2] s^{2}} .
$$

The subscripts $M$ and $O$ indicate the equilibrium level of a variable for the merging firm and an outsider and subscripts post refers to the equilibrium level the price after the merger. Hence, the steady state equilibrium profits are as follows

$$
\pi_{M}^{O L}=\frac{\alpha^{2} m(\rho+2 s)^{2}(\rho+s+2 m s)}{2(\rho+s)} ; \quad \pi_{O}^{O L}=\frac{\alpha^{2}(\rho+3 s)(\rho+s+m s)^{2}}{2(\rho+s)} .
$$

For the proof you can see Benchekroun (2003). 


\subsection{Closed-loop equilibrium}

Now, we look for the post-merger Nash equilibrium under the closed-loop strategies. The outcome is summarized by the following proposition:

Proposition 1 At the closed-loop Nash equilibrium, the steady state levels of the price and the output of merging firm and outsiders are

$$
\begin{gathered}
p_{\text {post }}^{C L}=A-q_{M}^{C L}-(n-m) q_{O}^{C L}, \\
q_{M}^{C L}=\beta m(\rho+(n-m+1) s)\left(\rho+\left(m^{2}-m+n+1\right) s\right), \\
q_{O}^{C L}=\beta(\rho+s(n+1))\left(\rho+\left(m^{2}-m+n\right) s\right),
\end{gathered}
$$

where

$$
\begin{aligned}
\beta= & (A-c) /\left[(n+1) \rho^{2}+\left(n\left(m^{2}-m+2 n+3\right)+2\right) \rho s\right. \\
& \left.+\left((n+1)\left(m^{2} n-m n+n^{2}+n+1\right)-m^{4}+m^{3}\right) s^{2}\right]
\end{aligned}
$$

which yields the steady state equilibrium profits

$$
\begin{gathered}
\pi_{M}^{C L}=\frac{1}{2} \beta^{2} m(\rho+(n-m+1) s)(\rho+(n+m+1) s)\left(\rho+\left(m^{2}-m+n+1\right) s\right)^{2} \\
\pi_{O}^{C L}=\frac{1}{2} \beta^{2}(\rho+s(n+1))^{2}\left(\rho+\left(m^{2}-m+n\right) s\right)\left(\rho+\left(m^{2}-m+n+2\right) s\right)
\end{gathered}
$$

Proof. Taking the first-order conditions w.r.t. $\bar{q}_{i}(t)$ and $q_{j}(t)$ and using (12) and (13), in turn, we have

$$
\begin{gathered}
\frac{\partial H^{M}(t)}{\partial \bar{q}_{i}(t)}=p(t)-c-\bar{q}_{i}(t)-\bar{\lambda}_{i}(t) s=0, \\
\frac{\partial H_{j}(t)}{\partial q_{j}(t)}=p(t)-c-q_{j}(t)-\lambda_{j}(t) s=0,
\end{gathered}
$$

which yields the optimal closed-loop output for, respectively, the insiders and outsiders as follows

$$
\begin{aligned}
& \bar{q}_{i}^{C L}(t)= \begin{cases}p(t)-c-\bar{\lambda}_{i}(t) s & \text { if } p(t)>c+\bar{\lambda}_{i}(t) s, \\
0 & \text { otherwise, }\end{cases} \\
& q_{j}^{C L}(t)= \begin{cases}p(t)-c-\lambda_{j}(t) s & \text { if } p(t)>c+\lambda_{j}(t) s, \\
0 & \text { otherwise. }\end{cases}
\end{aligned}
$$

The adjoint equations for the optimum are

$$
-\frac{\partial H^{M}(t)}{\partial p(t)}-\sum_{j=m+1}^{n} \frac{\partial H^{M}(t)}{\partial q_{j}(t)} \frac{\partial q_{j}^{C L}(t)}{\partial p(t)}=\frac{\partial \bar{\lambda}_{i}(t)}{\partial t}-\rho \bar{\lambda}_{i}(t)
$$




$$
-\frac{\partial H_{j}(t)}{\partial p(t)}-\sum_{\substack{k=m+1 \\ k \neq j}}^{n} \frac{\partial H_{j}(t)}{\partial q_{k}(t)} \frac{\partial q_{k}^{C L}(t)}{\partial p(t)}-m \sum_{i=1}^{m} \frac{\partial H_{j}(t)}{\partial \bar{q}_{i}(t)} \frac{\partial \bar{q}_{i}^{C L}(t)}{\partial p(t)}=\frac{\partial \lambda_{i}(t)}{\partial t}-\rho \lambda_{i}(t) .
$$

The transversality conditions are

$$
\lim _{t \rightarrow \infty} \bar{\mu}_{i}(t) \cdot p(t)=0 ; \quad \lim _{t \rightarrow \infty} \mu_{j}(t) \cdot p(t)=0 .
$$

From (19) and (20) we obtain

$$
\frac{\partial q_{j}^{C L}(t)}{\partial p(t)}=\frac{\partial q_{k}^{C L}(t)}{\partial p(t)}=\frac{\partial \bar{q}_{i}^{C L}(t)}{\partial p(t)}=1
$$

The difference between the closed-loop and open-loop solutions is due to these terms in equations (21) and (22) which are set equal to zero in the open-loop case. ${ }^{3}$ That is, when firms play closed-loop strategies, each firm inserts her information regarding the dependency of the other firms' supply policy on the current market price into the adjoint equation. The additional terms in the co-state equations (21) and (22) imply the strategic interaction among firms, which are not considered by definition in the open-loop solution. Furthermore, the adjoint equation of merging firm (21) is different from the adjoint equation of an outsider (22). Since there is a cartel inside the group of insiders, there is no strategic interaction among insiders while looking at (22) we recognize that in addition to the strategic interaction between each outsider and any of the insiders there are strategic interactions among outsiders.

Differentiating (12) and (13) w.r.t. the co-state variables and using (23), equations (21) and (22) can be rewritten as

$$
\begin{gathered}
-\sum_{i=1}^{m} \bar{q}_{i}(t)+\bar{\lambda}_{i}(t) s-\sum_{j=m+1}^{n} \bar{\lambda}_{i}(t) s=\frac{\partial \bar{\lambda}_{i}(t)}{\partial t}-\rho \bar{\lambda}_{i}(t), \\
-q_{j}(t)+\lambda_{j}(t) s-\sum_{\substack{k=m+1, k \neq j}}^{n} \lambda_{j}(t) s-m \sum_{i=1}^{m} \lambda_{j}(t) s=\frac{\partial \lambda_{i}(t)}{\partial t}-\rho \lambda_{i}(t) .
\end{gathered}
$$

Inducing symmetry assumption, we obtain

$$
\frac{\partial \bar{\lambda}(t)}{\partial t}=-m \bar{q}(t)+[(m-n+1) s+\rho] \bar{\lambda}(t)
$$

\footnotetext{
${ }^{3}$ In the open-loop solution, the adjoint equations for the optimum for insiders and outsiders are as follows, respectively

$$
-\frac{\partial H^{M}(t)}{\partial p(t)}=-\sum_{i=1}^{m} \bar{q}_{i}(t)+\bar{\lambda}_{i}(t) s=\frac{\partial \bar{\mu}_{i}(t)}{\partial t} ; \quad-\frac{\partial H_{j}(t)}{\partial p(t)}=-q_{j}(t)+\lambda_{j}(t) s=\frac{\partial \mu_{j}(t)}{\partial t}
$$
}




$$
\frac{\partial \lambda(t)}{\partial t}=-q(t)+\left[\left(-m^{2}-n+m+2\right) s+\rho\right] \lambda(t) .
$$

Differentiating (19) and (20) w.r.t. time and using (24) and (25) we find

$$
\begin{gathered}
\frac{d \bar{q}(t)}{d t}=\frac{d p(t)}{d t}-[-m \bar{q}(t)+[(m-n+1) s+\rho] \bar{\lambda}(t)] s \\
\frac{d q(t)}{d t}=\frac{d p(t)}{d t}-\left[-q(t)+\left[\left(-m^{2}-n+m+2\right) s+\rho\right] \lambda(t)\right] s .
\end{gathered}
$$

Using (11), (19) and (20) where a symmetry assumption is introduced for an individual firm output inside the group of insiders and also the group of outsiders, we can rewrite (26) and (27) as follows

$$
\begin{gathered}
\frac{d \bar{q}(t)}{d t}=s A+[(n-m-1) s-\rho] c+[(m-n) s+\rho] p(t) \\
-s(n-m) q(t)+[(n-m-1) s-\rho] \bar{q}(t) \\
\frac{d q(t)}{d t}=s A+c\left[\left(m^{2}+n-m-2\right) s-\rho\right]-s m \bar{q}(t) \\
+\left[\left(-m^{2}-n+m+1\right) s+\rho\right] p(t)+\left[\left(m^{2}-1\right) s-\rho\right] q(t) .
\end{gathered}
$$

$d \bar{q}(t) / d t=0, d q(t) / d t=0$ and $d p(t) / d t=0$, which are linear relationships between $p, \bar{q}$ and $q$, yield the steady state of the system and the equilibrium point is a saddle with (14), (15) and (16).

Keeping symmetry assumption in the group of insiders as well as the group of outsiders, the two groups are necessarily asymmetric. Because essentially there is a cartel among insiders while the rest of the market behave like dynamic Cournot competitors. These asymmetries between the two groups are not only with respect to the first-order conditions and controls but in particular with respect to the co-state amounts. By construction, the list of co-state values entails that the shadow price attached by any outsider will be systematically different from the shadow price attached to the price dynamics by one of the insiders. Considering (17) and (18), we can rewrite the FOCs for outsiders as $\bar{\lambda}(t)=p(t)-c-\bar{q}(t) / s$ and insiders as $\lambda(t)=p(t)-c-q(t) / s$. Then, taking into account the fact that the output level of an outsider is greater than the output level of a single insider, we have the following consequence

Corollary 1 The shadow price of an insider is greater than an outsider's $(\bar{\lambda}(t)>\lambda(t))$.

This entails that the proportional change of merging firm's profit, on account of alteration in the state equation, is more than that of an outsider. 


\section{The incentive to merge}

After finding the post-merger equilibrium, we are able to investigate the profitability of a horizontal merger with price dynamics in a Cournot competition. First, we figure out the minimum percentage of insiders which is required to make the merger profitable in the case of instantaneous price adjustment. Then, we evaluate merger profitability in the space $(m, s / \rho)$ for a given initial population of firms to perceive the role of price stickiness in stimulating merger incentives.

To deal with the above mentioned issues, we will consider the difference between the post-merger profit of the merging firm and sum of the individual profits of the insiders before the merger which has to be positive as a condition for merger profitability. That is, in an $n$-firm industry, $m$ firms will find it profitable to merge if and only if the merger profitability condition $\pi_{M}^{O L}-M \pi^{O L}>0$ (open-loop) or $\pi_{M}^{C L}-m \pi^{C L}>0$ (closed-loop) holds.

When the speed of price adjustment goes to infinity, Dockner and Gaunersdorfer (2001) and Benchekroun (2003) showed that when firms use feedback strategies mergers are always profitable irrespective of the number of insiders whereas we will show that it is not the case for the closed-loop (memoryless) and open-loop strategies and a sufficient proportion of firms is required. However, as compared to the open-loop, this proportion is very different when firms play closed-loop. Figure 1 illustrates corresponding results graphically. From this graph we can see that as the population of firms in the industry increases, the minimum proportion of firms that makes the merger profitable has a decreasing trend under the closed-loop strategies while it has an increasing trend under the open-loop strategies. Thus, we can argue that it is much more easier to maintain collusion among insiders in the closed-loop equilibrium than the open-loop. This difference is due to the fact that "open-loop" and "closed-loop" refer to the two different information structures. In both cases, everybody operate under the complete information but, as it is explained in previous section in detail, under the closed-loop information structure firms explicitly incorporate strategic interactions in the co-state equations while in the open-loop they do not. 
Figure 1: The lowest proportion of firms to be merged to make a profitable merger for the instantaneous price adjustment.

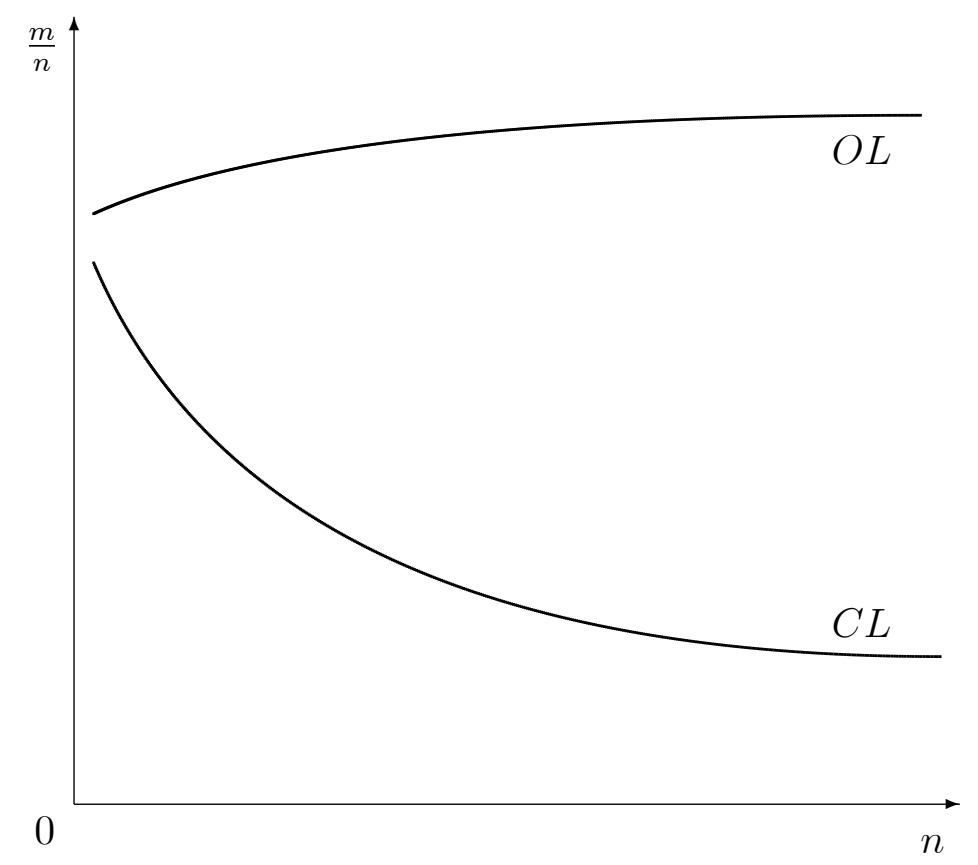

In figure 2, the region of parameters $s$ and $\rho$ for which merger of $m$ firms is profitable is represented by means of two dividing curves under the open-loop and closed-loop equilibria in a ten-firm industry. We provide this graph to show that in cases where price is too sticky, merger would be to the benefit of merging firm even if its market share is low.

In this figure we can see that in the open-loop equilibrium when the speed of adjustment goes to infinity, merger must involve at least eight insiders to become profitable. As it is investigated by Fershtman and Kamien ([8], pp. 1159-1161), in the limit where $s$ tends to infinity, the open-loop equilibrium (5) coincides with the static Cournot Nash equilibrium (7) and we know that in the static Cournot model merger is disadvantageous to the merging firm unless the market share of merging firm is sufficiently high (at least 80\%). However, in the closed-loop Nash equilibrium, as this figure clearly displays, merger of four firms in ten-firm industry is always profitable which is due to the closed-loop rule properties explained earlier. 
Figure 2: Merger profitability in the space $(m, s / \rho)$ for $n=10$

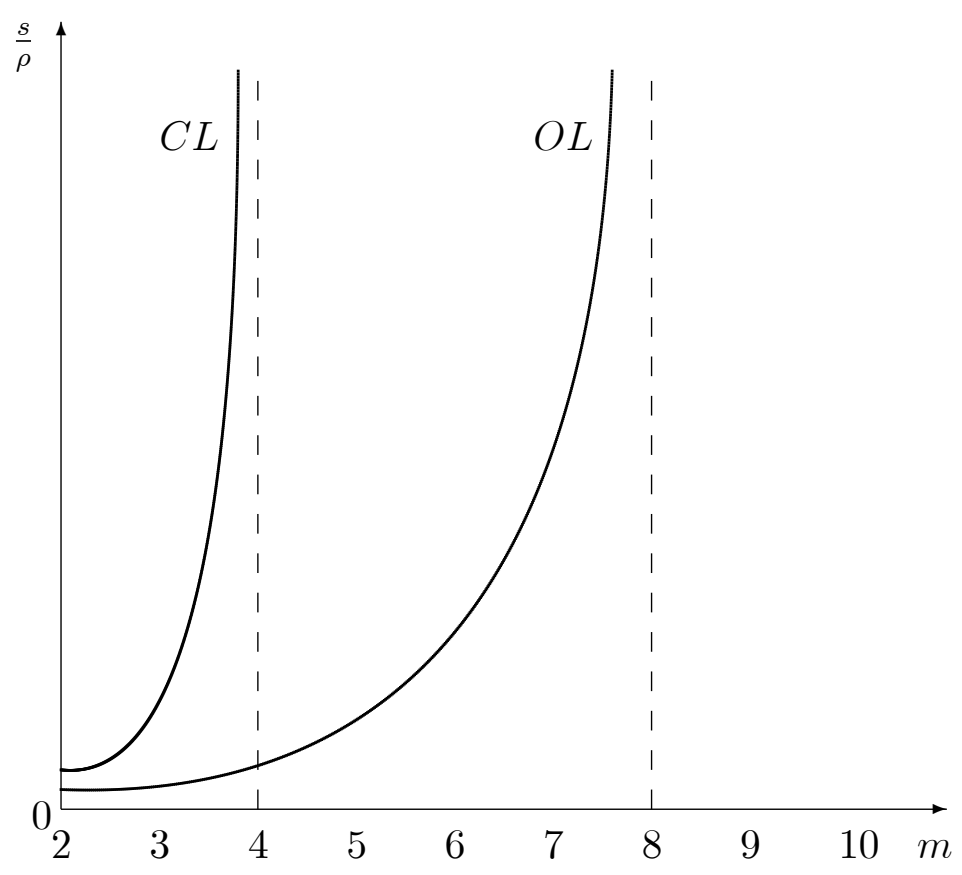

For a given level of discount rate, as the population of insiders decreases, the speed of price adjustment must reduce as well in order to make the merger profitable. This means that for a given rate of discounting, merger incentives are higher when the speed of price adjustment is slower. When price adjusts very slowly, the equilibrium prices both under the open-loop (5) and closed-loop (6) information structure approach to the competitive equilibrium price of the static game in which firms set price equal to marginal cost and as $s$ tends to zero, the equilibrium prices at the steady state, in either cases, are given by $(A+n c) /(n+1)$ which is precisely the competitive price as defined in (8). ${ }^{4}$ In games where firms behave like Bertrand competitors mergers are profitable because any price increase by insiders will be followed by a price increase from outsiders and in equilibrium prices in the industry are raised and this is to the benefit of all firms. Incentive to merge with Bertrand competition is extensively discussed by Deneckere and Davidson (1985).

\footnotetext{
${ }^{4}$ Also, the features of the feedback equilibrium in the limit where the discount rate tends to infinity is looked into by Fershtman and Kamien ([8], pp. 1159) and they demonstrated that in such circumstances, the feedback equilibrium coincides with the Bertrand equilibrium of the static game.
} 


\section{Conclusions}

Taking a differential game approach with sticky prices in an oligopolistic industry, we have analyzed the consequences of horizontal mergers both in the open-loop and the closed-loop solutions. In view of the fact that we would like to concentrate on the incentives to merge that are generated by price dynamics, it is assumed that there is no cost efficiency in our model. It turns out that for a given amount of interest rate, merger incentives are higher when the mechanism governing price adjustment is very slow. When price is very sticky, the dynamic Cournot equilibrium prices approach to the competitive equilibrium price of the static game in which firms set price equal to marginal cost. Firms would like to play the correct Cournot equilibrium but they cannot because price adjusts very slowly and in this aggressive environment they have an incentive to decrease the number of competitors through merger in order to make a slight correction in output setting mistakes and recover what they are losing.

Moreover, our results suggest that the relative number of firms that is required for merger to be profitable has two divergent trends under open-loop and closed-loop information structures. When firms play cloesd-loop, it is a decreasing function of the population of firms in the industry while for the open-loop it is the opposite. Accordingly, the larger the relevant information set, the higher is the possibility of collusion between firms. Given that pushing competition has a contradictory outcome under the closed-loop rule, it is worthwhile for policy makers and antitrust authorities to consider as well the nature of competition in the industry. 


\section{References}

[1] Benchekroun, H., 2003. The closed-loop effect and the profitability of horizontal mergers. Canadian Journal of Economics 36, 546-565.

[2] Cellini, R., Lambertini, L., 2004. Dynamic oligopoly with sticky prices: Closed-loop, feedback and open-loop solutions. Journal of Dynamical and Control Systems 10, 303-314.

[3] Cheung, F.K., 1992. Two remarks on the equilibrium analysis of horizontal mergers. Economics Letters 40, 119-23.

[4] Daughety, A.F., 1990. Beneficial concentration. American Economic Review, 80, 12311237.

[5] Deneckere, R. and Davidson, C., 1985. Incentives to Form Coalitions with Bertrand Competition. RAND Journal of Economics 16, 473-86.

[6] Dockner, E.J., Gaunersdorfer, A., 2001. On the profitability of horizontal mergers in industries with dynamic competition. Japan and the World Economy 13, 195-216.

[7] Farrell, J. and Shapiro, C., 1990. Horizontal Mergers: An Equilibrium Analysis. American Economic Review 80, 107-26.

[8] Fershtman, C. and Kamien, M. I., 1987. Dynamic duopolistic competition with sticky prices. Econometrica 55, 1151-1164.

[9] Gaudet, G., Salant, S.W, 1991. Increasing the profits of a subset of firms in oligopoly models with strategic substitutes. American Economic Review 81, 658-665.

[10] Gaudet, G., Salant, S.W, 1992. Thowards a theory of hrizontal mergers. In: Norman, G., La Manna, M. (Eds.), The New Industrial Economics: Recent Developments in Industrial Organization, Oligopoly and Game Theory. Elgar.

[11] Levin, D., 1990. Horizontal mergers: the 50-percent benchmark. American Economic Review 80, 1238-45

[12] Perry, M.K. and Porter, R.H., 1985. Oligopoly and the Incentive for Horizontal Merger. American Economic Review. 75, 219-27.

[13] Salant, S.W., Switzer, S. and Reynolds, R.J., 1983. Losses from Horizontal Merger: The Effects of an Exogenous Change in Industry Structure on Cournot-Nash Equilibrium. Quarterly Journal of Economics 98, 185-213.

[14] Simaan, M. and Takayama, T., 1978. Game theory applied to dynamic duopoly problems with production constraints. Automatica 14, 161-166. 


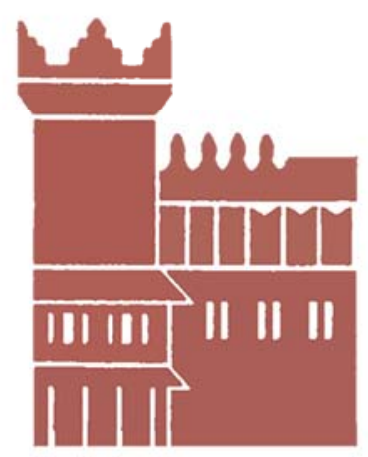

Alma Mater Studiorum - Università di Bologna DEPARTMENT OF ECONOMICS

Strada Maggiore 45

40125 Bologna - Italy

Tel. +39051 2092604

Fax +390512092664

http://www.dse.unibo.it 